\title{
HEPATIC ENCEPHALOPATHY DUE TO HEPATITIS A - CAN AGE PREDICT NEED FOR LIVER TRANSPLANT?
}

\author{
Kruti Dhaval Gandhi ${ }^{1}$, Ira Shah ${ }^{2}$. \\ ${ }^{1}$ Seth G S Medical College, Mumbai, India, \\ 2Pediatric GI and Hepatology, Levioza Health Care, Mumbai, India.
}

\section{KEYWORDS}

Hepatitis A, Hepatic Encephalopathy

\author{
ARTICLE HISTORY \\ Received 6 September 2020 \\ Accepted 21 November 2020
}

\section{Clinical Problem:}

\section{Case 1}

An 8-year-old female child presented with fever and lethargy for 8 days, right hypochondriac pain and abdominal distension for 5 days, vomiting for 3 days, oliguria and irrelevant speech for 2 days. There was no hematemesis, jaundice, or bleeding from any site. On examination, she was icteric, had anasarca with altered sensorium with blood pressure $98 / 60 \mathrm{~mm}$ of $\mathrm{Hg}$. There was no hepatosplenomegaly, meningeal signs, or focal neurological deficit. Other systems were normal. Investigations showed hemoglobin of 11 $\mathrm{gm} / \mathrm{dl}$, white blood cell (WBC) count of $8400 /$ cumm, platelets of $1,71,000 /$ cumm, bilirubin of $4.4 \mathrm{mg} / \mathrm{dl}$, SGOT of $2890 \mathrm{IU} / \mathrm{L}$, SGPT of $4215 \mathrm{IU} / \mathrm{L}$, total proteins of $5.7 \mathrm{gm} / \mathrm{dl}$, albumin of $2.7 \mathrm{gm} / \mathrm{dl}$, prothrombin time (PT) of $39 \mathrm{sec}$, partial thromboplastin time (PTT) of $93.3 \mathrm{sec}$ and ammonia of $300 \mathrm{mg} / \mathrm{dl}$. Her Hepatitis A IgM was positive. HBsAg, Anti hepatitis $C$ virus (HCV), leptospira IgM, dengue IgM was negative. Ultrasound abdomen showed moderate ascites with right sided pleural effusion. The child was treated with dextrose, lactulose, metronidazole, and L-ornithine-L-aspartate following which she gradually improved and recovered.

\section{Case 2}

An 8-year-old male child presented with abdominal pain for 7 days, jaundice for 4 days, increased sleepiness for 2 days. There was edema or no bleeding from any site. On examination, he had icterus, hepatomegaly, ascites. There were no meningeal signs or focal neurological deficit. Other systems were normal. Investigations showed hemoglobin of $8.2 \mathrm{gm} / \mathrm{dl}$, WBC of $5500 /$ cumm, platelets of 2,25,000/cumm, bilirubin of $18.13 \mathrm{mg} / \mathrm{dl}$ SGOT of $352 \mathrm{IU} / \mathrm{L}$, SGPT of $713 \mathrm{IU} / \mathrm{L}$, total proteins of $7.0 \mathrm{gm} / \mathrm{dl}$, albumin of $3.6 \mathrm{gm} / \mathrm{dl}$, PT of $12 \mathrm{sec,} \mathrm{PTT}$ of $23.8 \mathrm{sec}$. His Hepatitis A IgM was positive. HBsAg, Anti HCV, Leptospira IgM, Dengue IgM were negative. The child was treated with intravenous (IV) fluids, lactulose and L-ornithine-L-aspartate following which he gradually improved and recovered.

Address for Correspondance: Kruti Dhaval Gandhi, 501, Crescent Heights, Forjett Street, Mumbai- 400036, Maharashtra, India.

Email: krutig96@gmail.com

(C)2021 Pediatric Oncall
Can age predict need for liver transplant in children with Hepatitis $A$ virus infection?

\section{Discussion:}

Viral Hepatitis $A$ is one of the most frequent of the infectious liver diseases in the pediatric population. Hepatitis A presents as a mild self-limited disease where symptoms may include anorexia, nausea, vomiting, low grade fever, myalgia, arthralgia, jaundice, dark coloured urine, clay coloured stools and right upper quadrant pain. ${ }^{1,2}$ Approximately $85 \%$ of individuals infected with hepatitis A virus (HAV) have full clinical and biochemical recovery within a 3-month period with nearly all individuals recovering within 6 months. In about $10 \%$ to $20 \%$ of symptomatic patients, a prolonged and relapsing course can occur lasting several months. ${ }^{2,3}$ Hepatic encephalopathy due to hepatitis $A$ is rare and has been reported to be around $0.4 \% .{ }^{4}$ Precipitants of hepatic encephalopathy in patients of Hepatitis $A$ include conditions that increase the nitrogen overload such as constipation, gastrointestinal bleeding, blood transfusions, azotemia, infection, hypokalemia and conditions that decrease toxin clearance such as hypotension and dehydration via fluid restriction, excessive diuresis, diarrhoea. ${ }^{5}$ Generally, hepatitis A-related ALF has a spontaneous survival rate of $69 \%$; the remaining $31 \%$ require emergency liver transplant (ELT) or die. ${ }^{6}$ Globally, the estimated mortality rate for Hepatitis $A$, is $0.1 \%$ for children less than 15 years of age, $0.3 \%$ for adults of age 15 to 39 years and $2.1 \%$ for adults of age 40 years and older. $^{7}$ The annual mortality rate for children 28 to 364 days of birth is about 12 per 100,000 people, for 1 to 4 years of age is about 2 per 100,000 people, for 5 to 9 years of age is about 0.2 to 0.4 per 100,000 people and for 10 to 15 years is about 0.2 to 0.3 per 100,000 people. [8] Both our patients were 8 years of age suggesting that risk of mortality was extremely low. Even though bilirubin was high in the second child, he responded to conservative management. Thus, age may also be a criteria to determine need for liver transplant in Hepatitis A encephalopathy.

\section{Compliance with ethical standards}

Funding: None

Conflict of Interest: None 


\section{References:}

1. Hepatitis A | World Health Organisation; 2017. Available at URL: http://www.who.int/en/news-room/fact-sheets/ detail/hepatitis-a. Accessed on 25th May 2018

2. Cuthbert JA. Hepatitis A:old and new. Clin Microbiol Rev. 2001; 14:38-58.

3. Koff RS. Clinical manifestations and diagnosis of hepatitis A virus infection. Vaccine. 1992; 10 Suppl 1:S15-S17.

4. Cervio G, Trentadue J, Agostino DE, Luque C, Giorgi MA, et al. Decline in HAV-associated fulminant hepatic failure and liver transplant in children in Argentina after the introduction of a universal hepatitis A vaccination program. Hepat Med. 2011; 3:99-106.

5. Al Sibae MR, McGuire BM. Current trends in the treatment of hepatic encephalopathy. Ther Clin Risk Manag. 2009;
5:617-626.

6. Taylor RM, Davern T, Munoz S, et al. Fulminant hepatitis A virus infection in the United States: incidence, prognosis, and outcomes. Hepatology. 2006;44:1589-1597.

7. Jacobsen $\mathrm{KH}$. The Global Prevalence of Hepatitis $A$ Virus Infection and Susceptibility : A Systemic Review. Geneva, Switzerland: World Health Organization; 2009. Available at URL: http://apps.who.int/iris/ bitstream/handle/10665/70180/WHO_IVB_10.01_eng. pdf; jsessionid =639E4E504ACCF9B43E4B10C360EAEC47? sequence $=1$. Accessed on 25th May 2018

8. Hepatitis A in India: Health Statistics, Demographics Affected; Health Grove by Graphiq. Available at URL: http://global-disease-burden.healthgrove.com/l/27251/ Hepatitis-A-in-India. Accessed on 25th May 2018 